\title{
Erratum to: Time to patent at the USPTO: the case of emerging entrepreneurial firms
}

\author{
Kenneth Zahringer $^{1}$ - Christos Kolympiris ${ }^{2}$. \\ Nicholas Kalaitzandonakes ${ }^{3}$ (iD
}

\section{Erratum to: J Technol Transf DOI 10.1007/s10961-016-9524-1}

The original version of this article unfortunately contained errors in Tables 2, 3, 4 and 5. The corrected tables are given below.

The online version of the original article can be found under doi:10.1007/s10961-016-9524-1.

Nicholas Kalaitzandonakes

kalaitzandonakesn@missouri.edu

Kenneth Zahringer

ZahringerKA@missouri.edu

Christos Kolympiris

c.kolympiris@bath.ac.uk

1 Economics and Management of Agrobiotechnology Center, Department of Agricultural and Applied Economics, University of Missouri, Columbia, MO, USA

2 School of Management, University of Bath, Bath, UK

3 Department of Agricultural and Applied Economics, University of Missouri, Columbia, MO, USA 


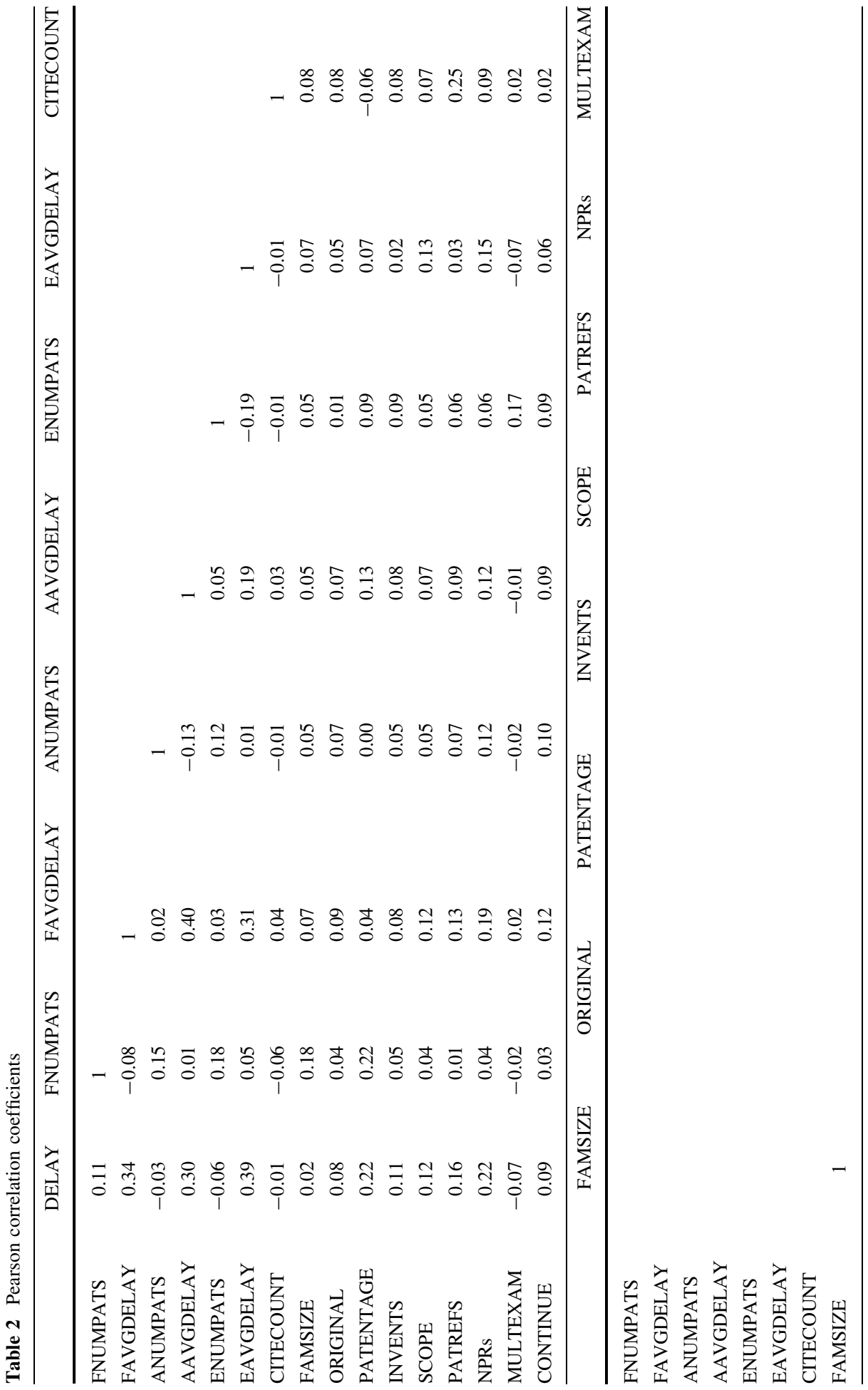




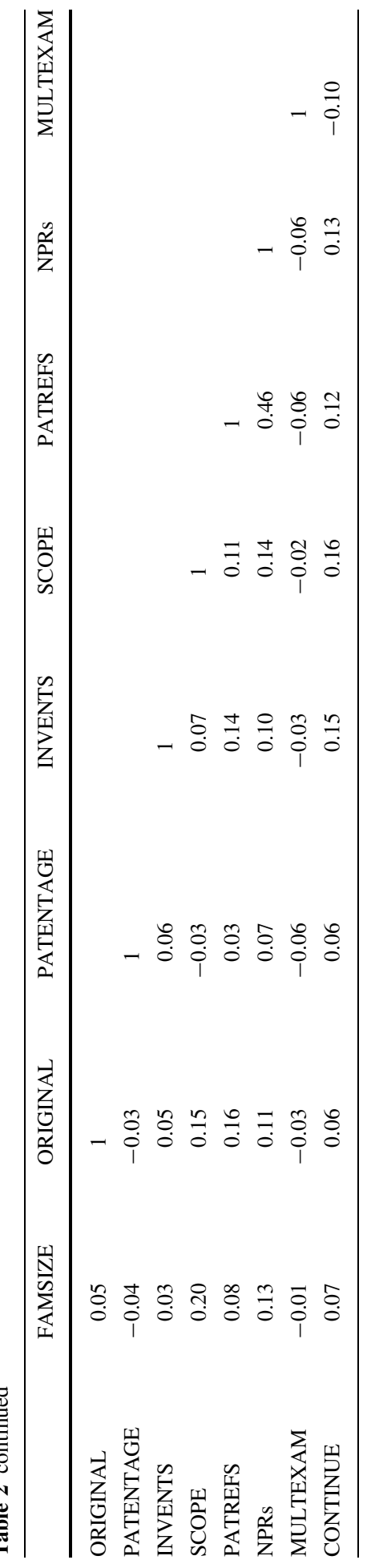




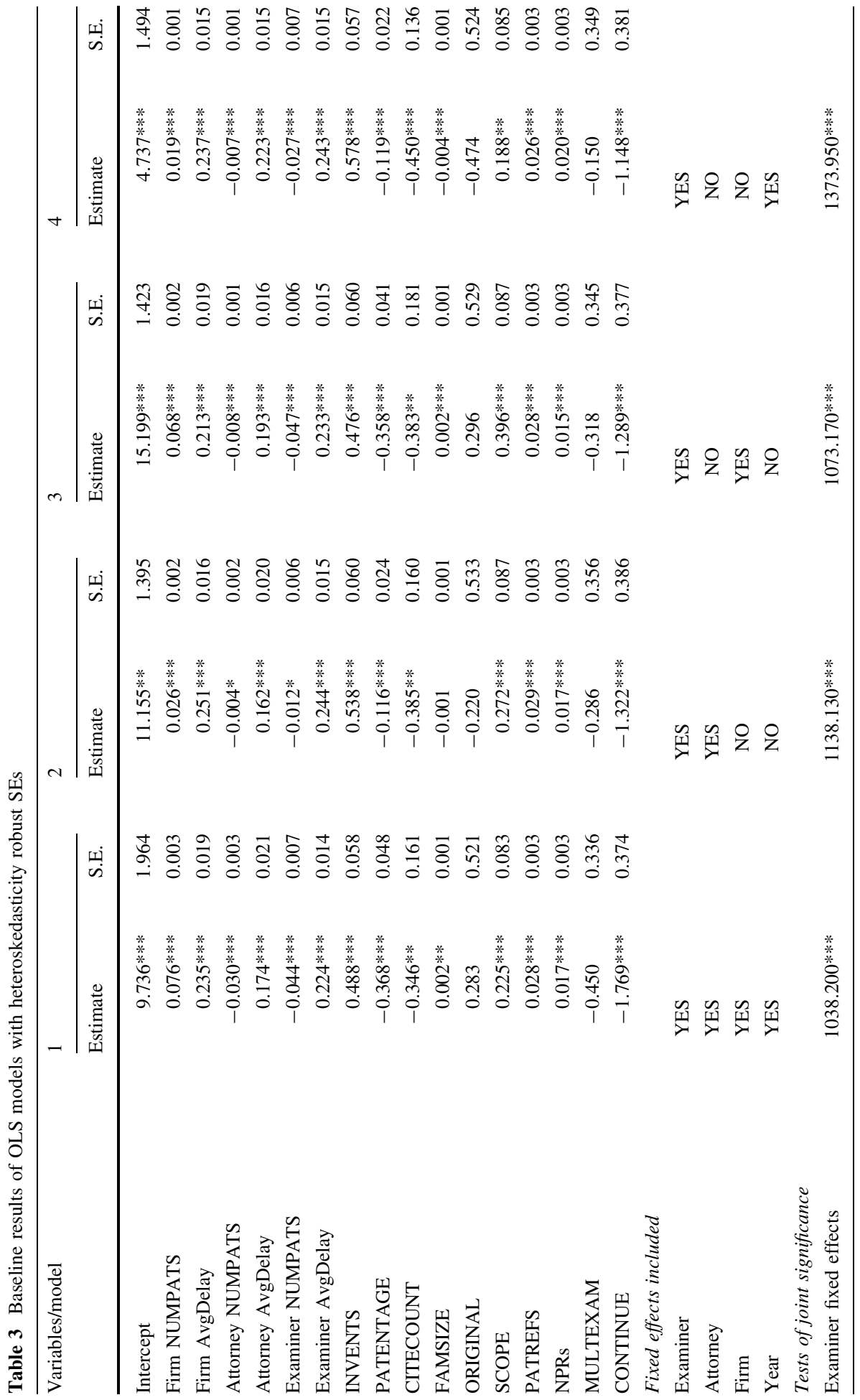




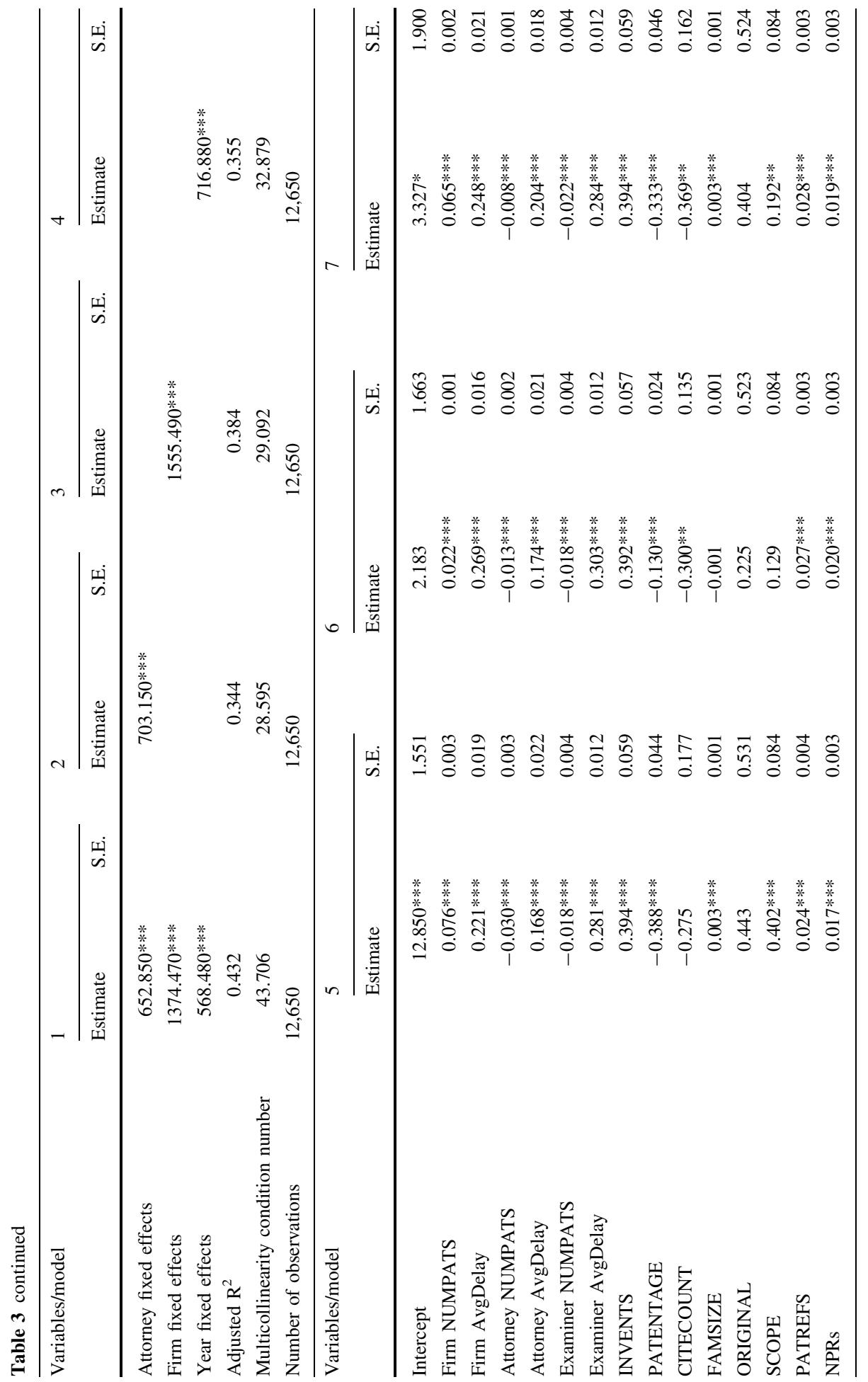




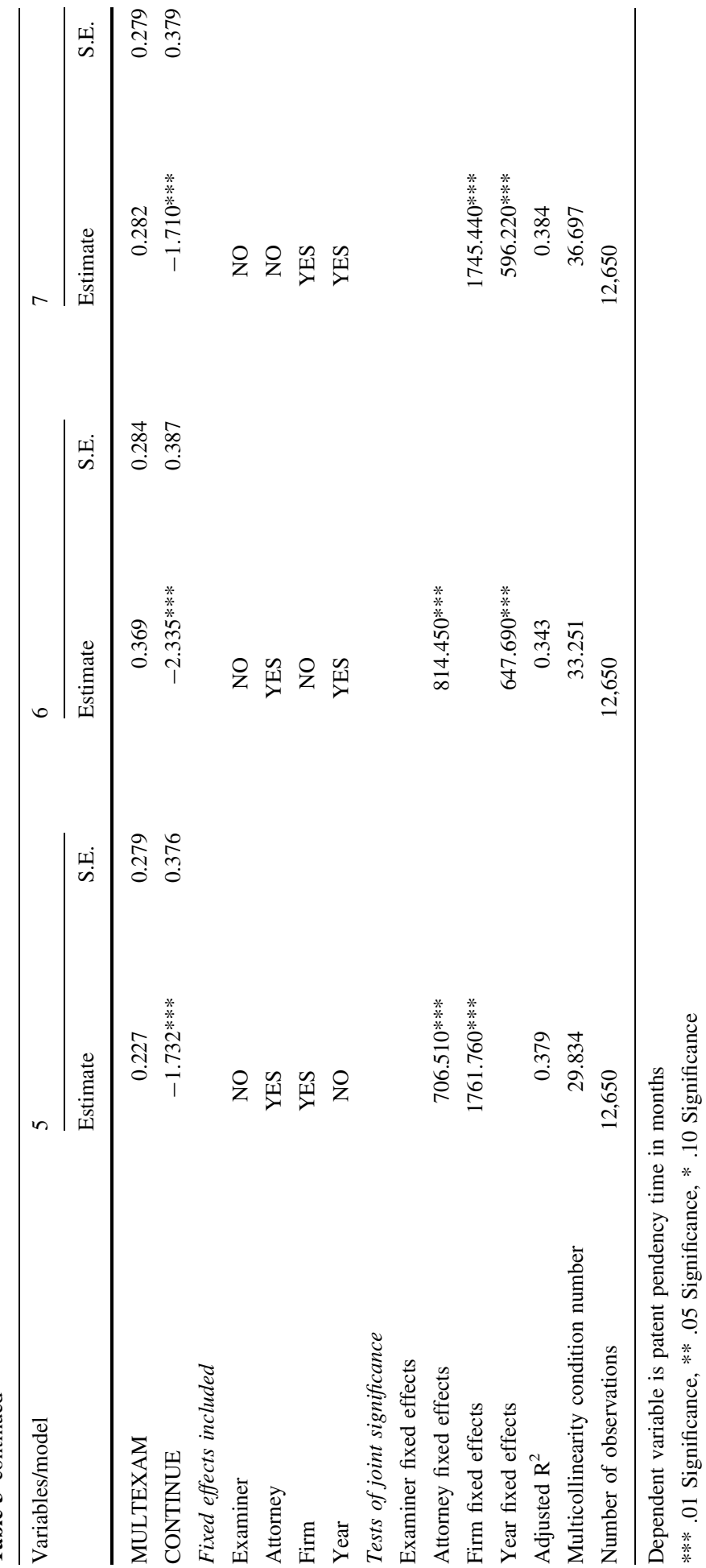




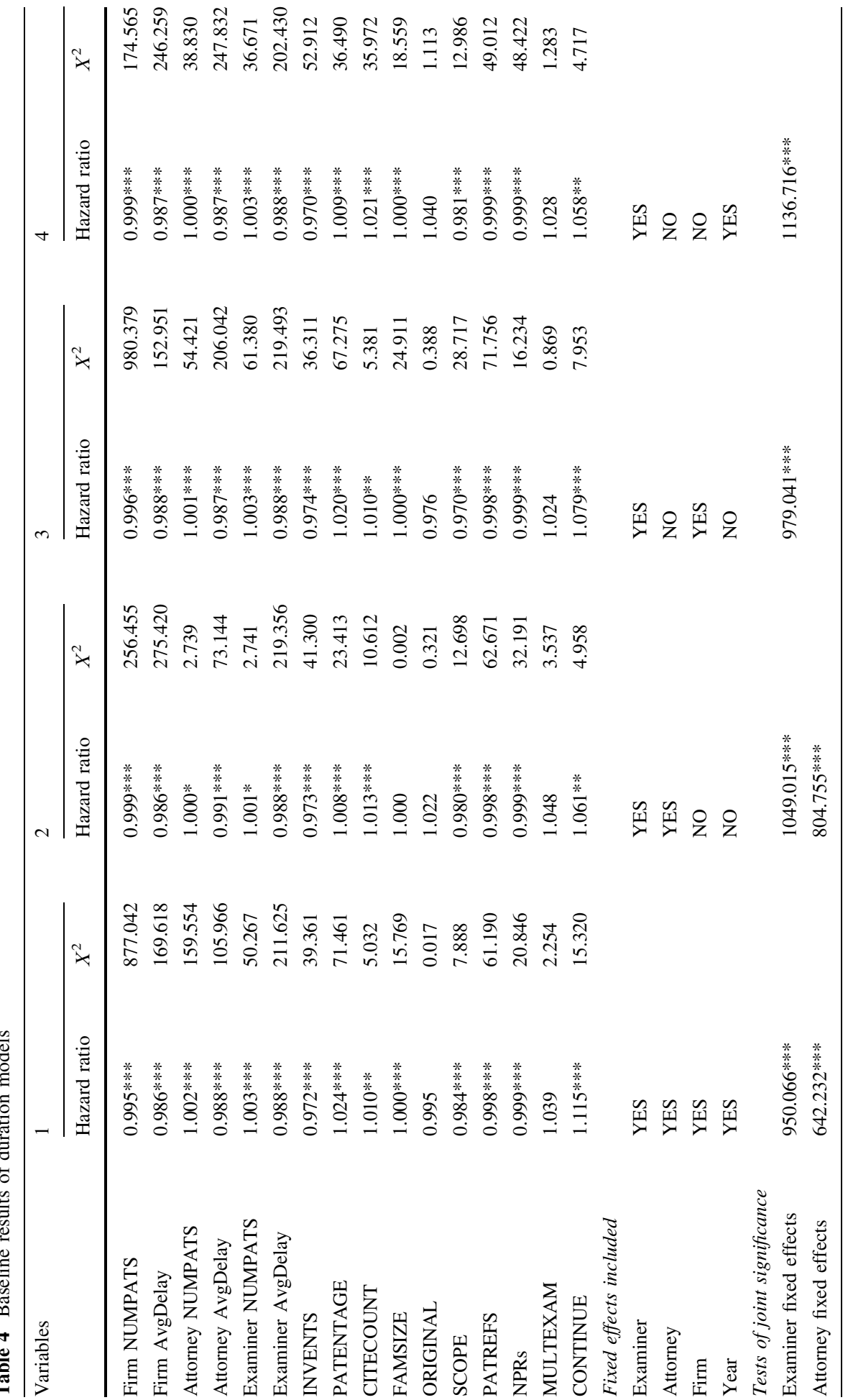




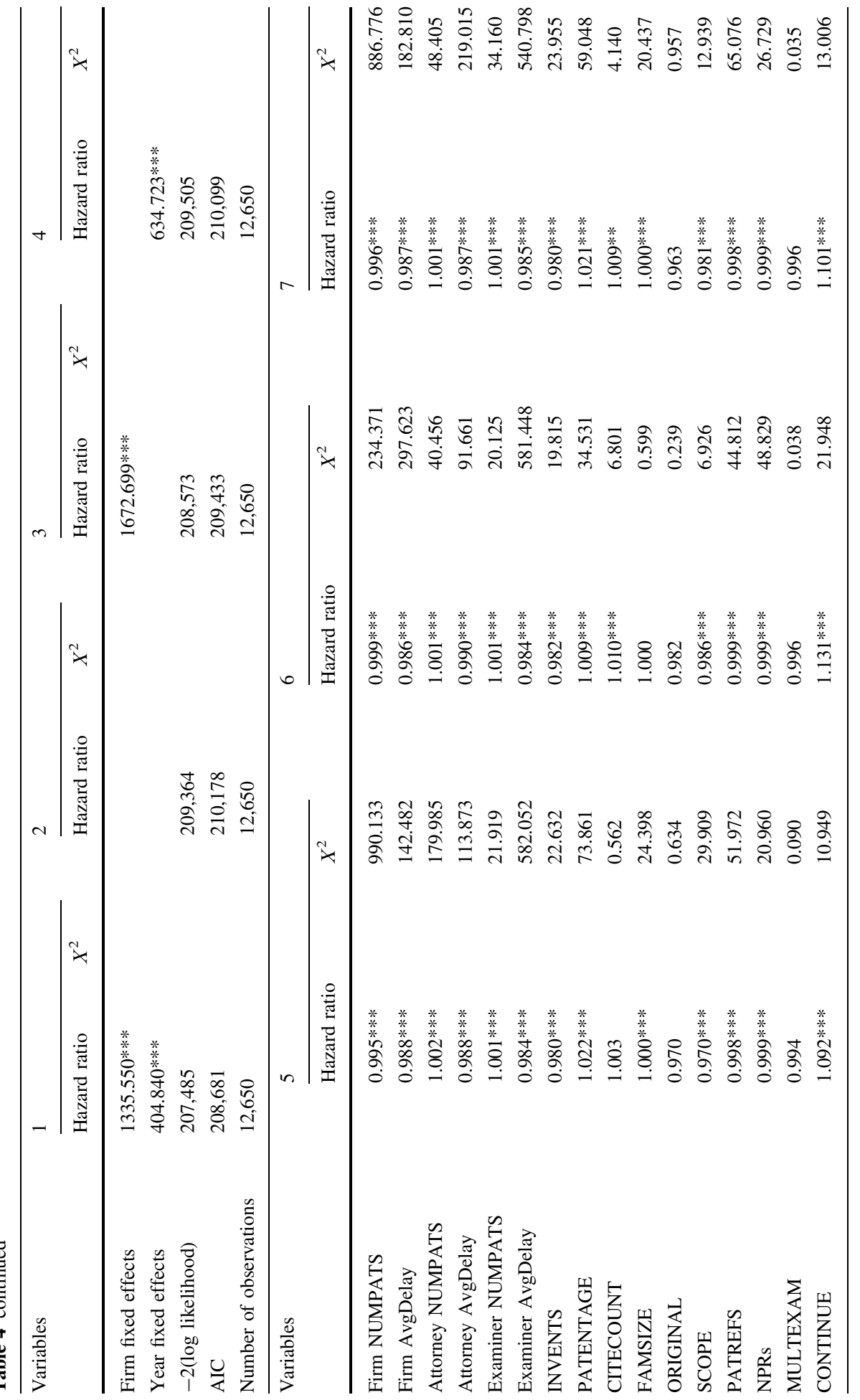




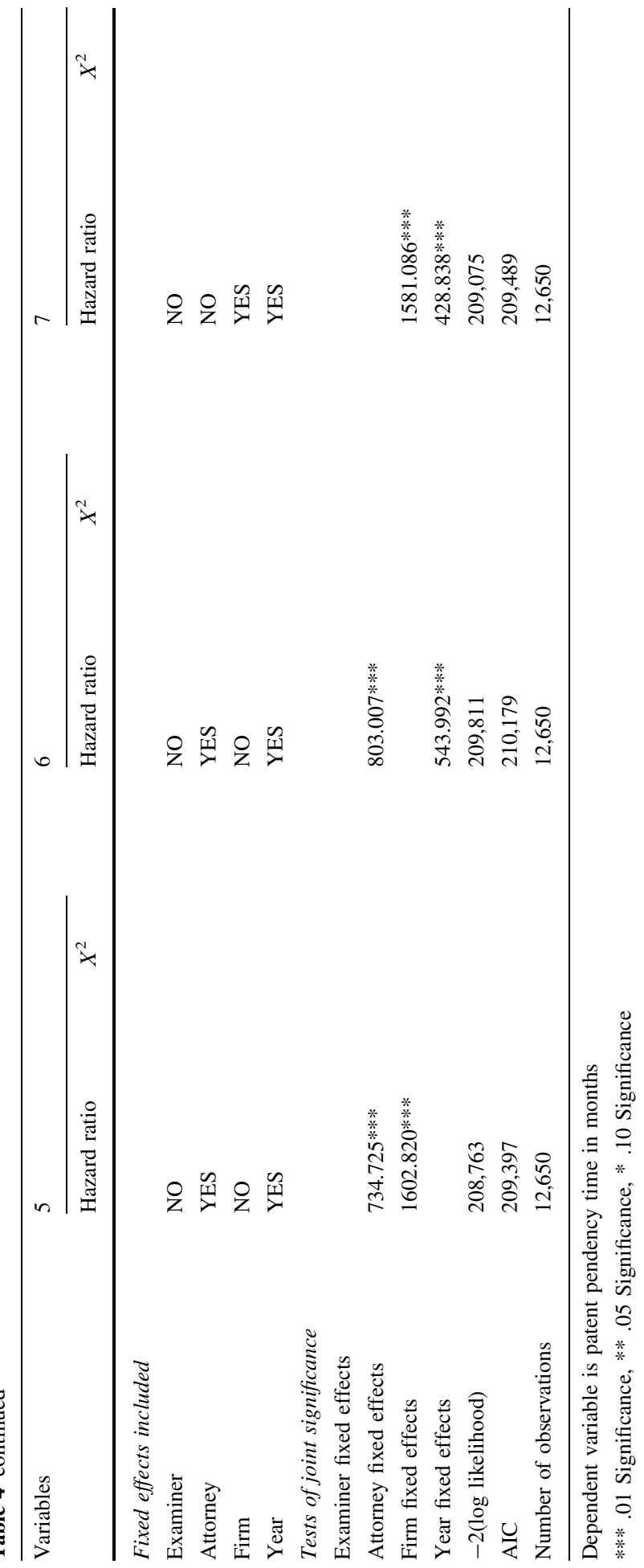




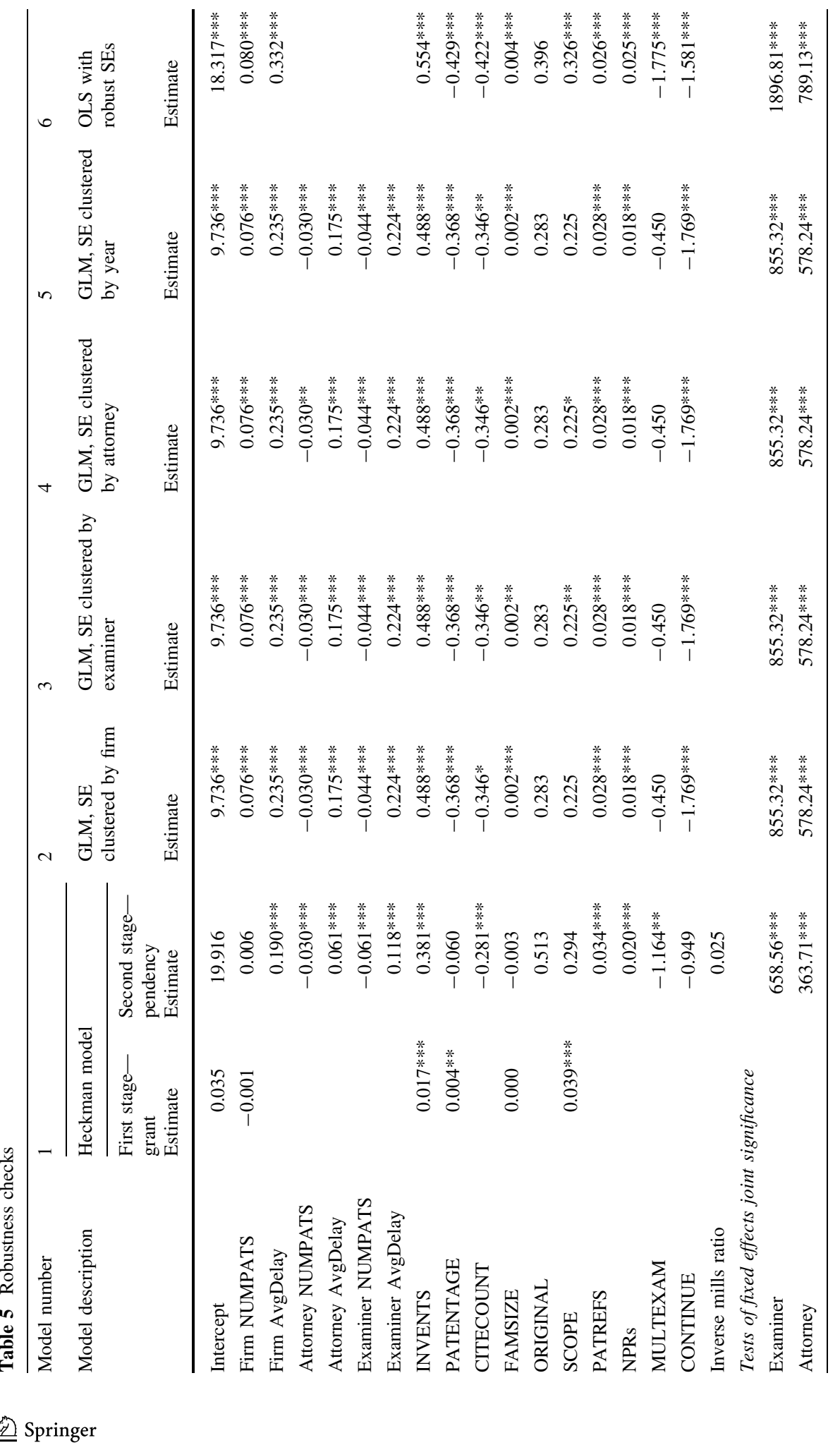




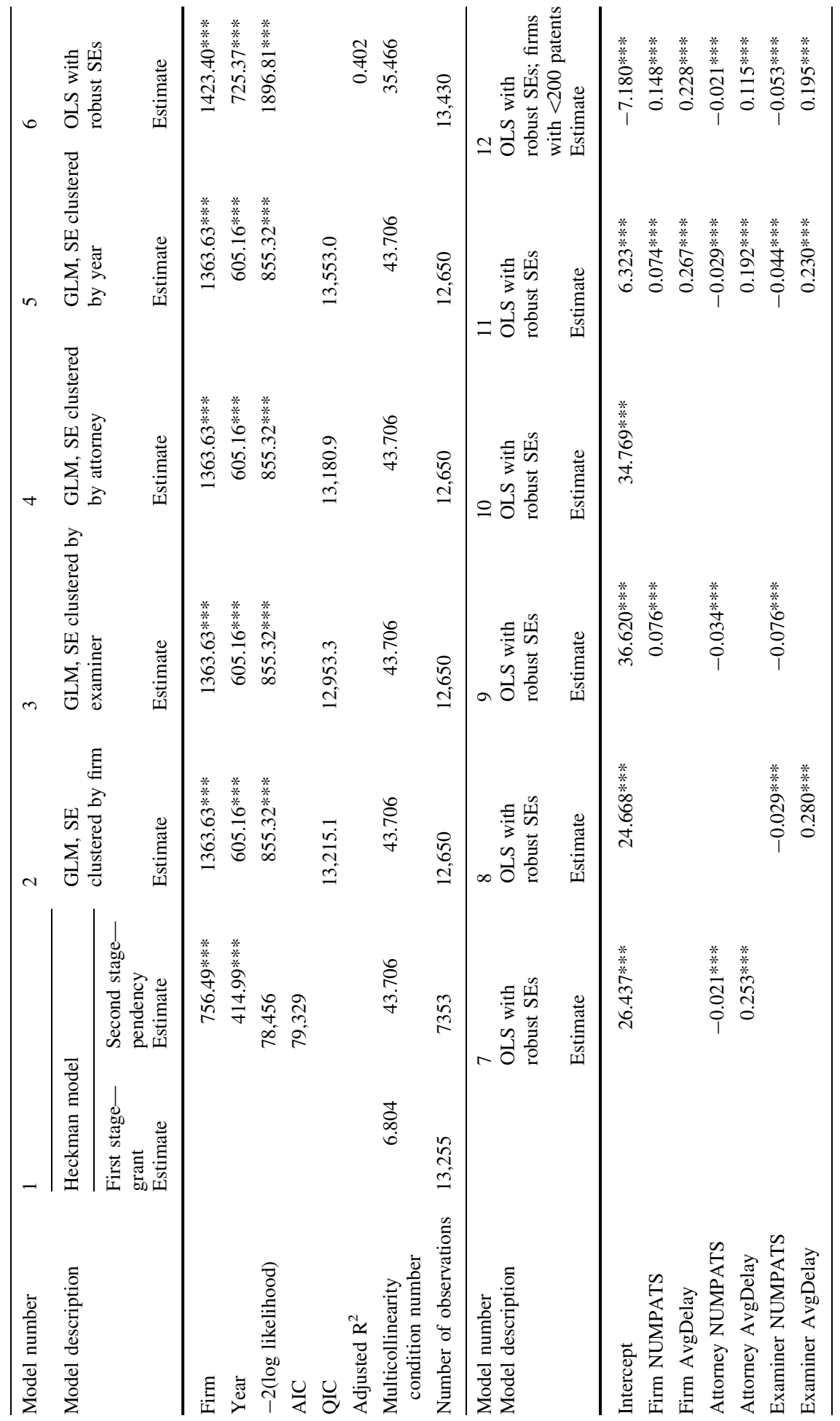




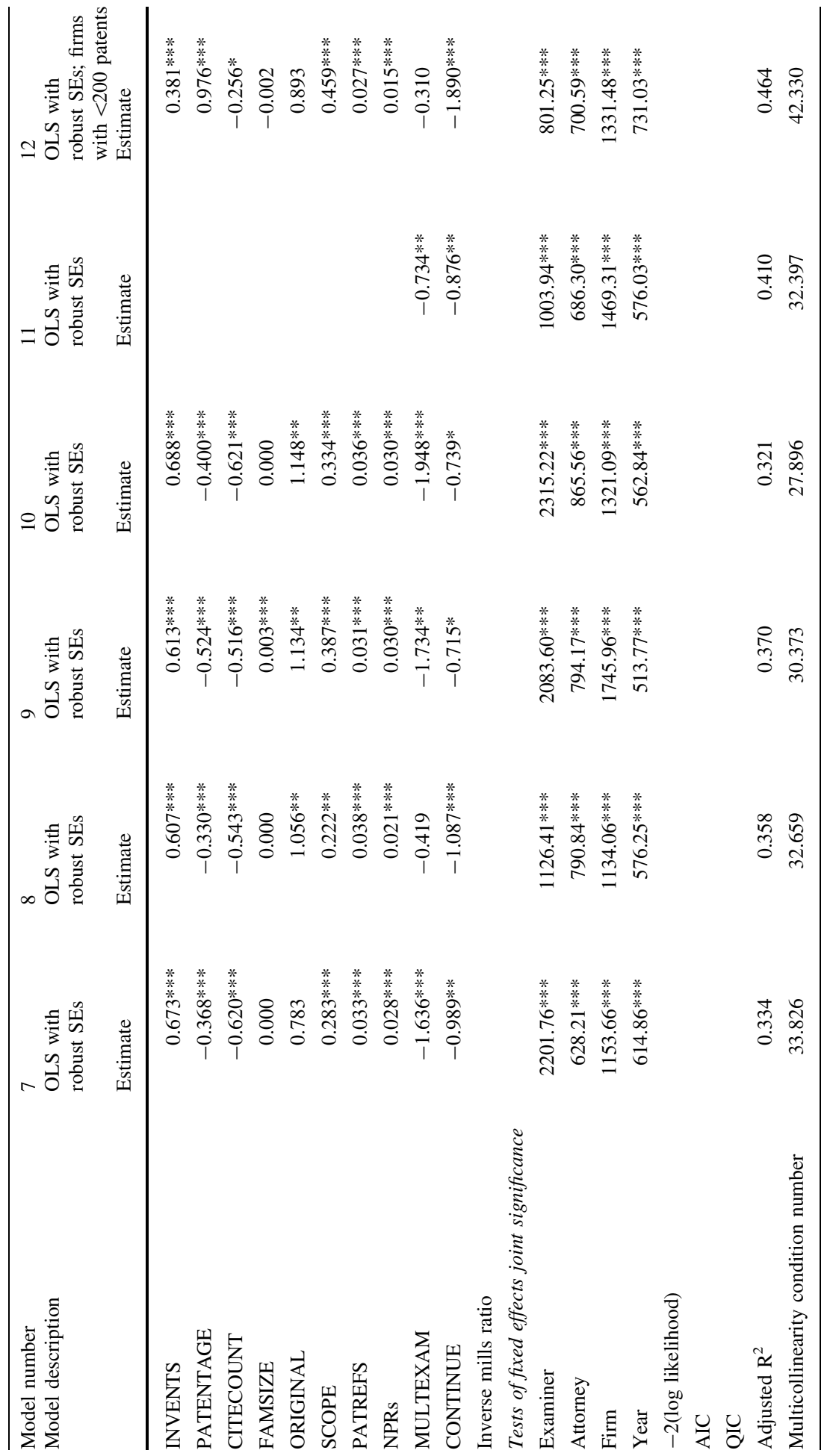




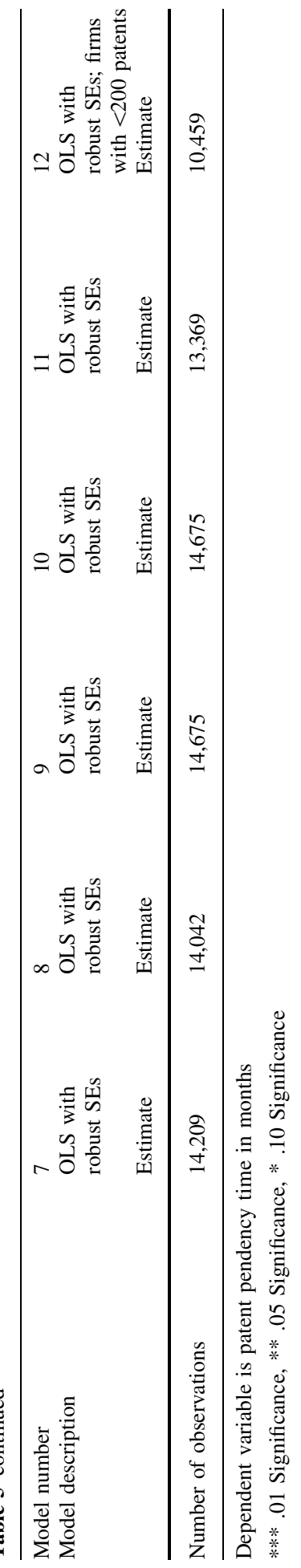

